\title{
Suscetibilidade de biótipos de milhã (Digitaria ciliaris) a herbicidas inibidores da enzima ACCase ${ }^{1}$
}

\author{
Susceptibility of crabgrass biotypes (Digitaria ciliaris) to ACCase inhibitor \\ herbicides
}

\author{
Lisiane Camponogara Fontana ${ }^{2}$; Dirceu Agostinetto ${ }^{3}$; André da Rosa Ulguim² ${ }^{2}$ Claudia de \\ Oliveira $^{2}$; Ana Claudia Langaro ${ }^{2}$
}

Resumo - As espécies pertencentes ao gênero Digitaria incluem-se entre as principais plantas daninhas que infestam as lavouras de arroz e de soja. $\mathrm{O}$ objetivo deste trabalho foi avaliar a suscetibilidade diferencial de biótipos de milhã, encontrados em lavouras no Rio Grande do Sul (RS), aos herbicidas cyhalofop ou clethodim. Conduziram-se três experimentos em casa de vegetação, no período de 2009 a 2011. Sementes de Digitaria spp. foram coletadas em diferentes localidades no RS, abrangendo áreas de produção de arroz irrigado e soja, totalizando 169 biótipos. Para verificar a suscetibilidade dos biótipos aos herbicidas, aplicou-se $225 \mathrm{~g}$ i.a. ha ${ }^{-1}$ de cyhalofop ou $96 \mathrm{~g}$ i.a. ha $^{-1}$ de clethodim, sendo selecionados oito biótipos de Digitaria ciliaris que apresentaram maior e menor tolerância após aplicação dos herbicidas, para os estudos de curva de dose resposta. Verificou-se que os biótipos que apresentaram maior tolerância ao cyhalofop os oriundos de Santa Vitória do Palmar, Viamão, Santa Bárbara do Sul e Cruz Alta, com controles entre 50 e $60 \%$. Os biótipos de milhã selecionados apresentaram-se suscetíveis ao herbicida clethodim, com controle superior a $90 \%$. As populações de D. ciliaris coletadas em lavouras de arroz e soja dos municípios do RS foram suscetíveis ao herbicida clethodim, quando aplicado na dose recomendada, enquanto que a suscetibilidade da espécie ao herbicida cyhalofop foi diferencial entre biótipos.

Palavras-chaves: arroz, soja, cyhalofop, clethodim, acetil coenzima A carboxilase

Abstract - Species belonging to Digitaria genus are including among major weeds infesting rice and soybeans crops. The objective of this study was to evaluate the differential susceptibility of crabgrass biotypes crops at Rio Grande do Sul State, to clethodim or cyhalofop herbicides. Three experiments were conducted in greenhouse conditions, in the period of 2009-2011 agricultural years. Seeds of Digitaria spp. were collected from different places in the State, covering areas of irrigated rice production and soybeans crops, totalizing 169 biotypes. To evaluate the biotypes sensitivity to the herbicides was applied $225 \mathrm{~g}$ a.i. $\mathrm{ha}^{-1}$ of cyhalofop or $96 \mathrm{~g}$ a.i. ha ${ }^{-1}$ of clethodim, being selected eight Digitaria ciliaris biotypes with higher and lower tolerances after herbicides application to the studies of response curve doses. It was found four biotypes with higher tolerance to cyhalofop coming from Santa Vitória do Palmar, Viamão, Santa

\footnotetext{
${ }^{1}$ Recebido para publicação em 03/08/2013 e aceito em 25/03/2014.

2 Aluno do Programa de Pós-graduação em Fitossanidade da Universidade Federal de Pelotas (UFPel), Campus Universitário Capão do Leão, Caixa Postal 354, 96010-900, Pelotas-RS. E-mail: lisicamponogara@gmail.com (Autor para correspondência).

${ }^{3}$ Professor da Faculdade de Agronomia Eliseu Maciel, UFpel.
} 
Barbara do Sul and Cruz Alta County, with controls between 50 and 60\%. Biotypes of crabgrass were susceptible to clethodim herbicide, with a control superior greater than $90 \%$. The D. ciliaris populations collected in rice and soybeans crops in RS were susceptible to clethodim herbicide when the application was made at recommended dose, while specie susceptibility cyhalofop herbicide was differential among biotypes.

Keywords: rice, soybean, cyhalofop, clethodim, acetyl-coenzyme A carboxylase

\section{Introdução}

A ocorrência de plantas daninhas está entre os principais fatores limitantes do potencial produtivo das culturas, sendo as perdas variáveis em função de características da espécie infestante e das práticas de manejo empregadas na lavoura, como foi observado na cultura do arroz irrigado (Balbinot Jr. et al., 2003; Galon et al., 2007) e da soja (Fleck et al., 2006; Barroso et al., 2010).

As espécies pertencentes ao gênero Digitaria, popularmente conhecidas como milhã, incluem-se entre as principais plantas daninhas que infestam as lavouras de arroz (Silva \& Durigan, 2009) e de soja (LópezOvejero et al., 2006; Barroso et al., 2010). Sua presença ocasiona perdas de produtividade pela competição por recursos limitantes como água, luz e nutrientes, tornando as medidas de controle indispensáveis para a manutenção da produtividade das culturas (Fontana, 2011).

O controle eficaz e uniforme das espécies presentes na área e a possibilidade de realização de controle em grandes extensões de área, em curto período de tempo são as principais vantagens do uso de herbicidas para o controle de plantas daninhas (Vargas \& Roman, 2006). Entre os herbicidas utilizados em lavouras de arroz irrigado para controle de milhã destaca-se o cyhalofop e, para a cultura da soja, o clethodim, o que decore da eficiência de controle e seletividade as culturas (Reunião..., 2008; SOSBAI, 2009).

Os herbicidas cyhalofop e clethodim possuem como mecanismo de ação a inibição da acetil coenzima A carboxilase (ACCase). Eles promovem inibição enzimática, bloqueando a síntese de lipídeos nas plantas suscetíveis (Burke et al., 2006), prejudicando a formação das paredes celulares e desestruturando os tecidos em formação (Vidal \& Merotto Jr., 2001). A aplicação de herbicidas gera pressão de seleção sobre a flora infestante. As duas principais formas de resposta das plantas daninhas à seleção herbicida são a mudança na flora, pela seleção de espécies tolerantes, ou a seleção intraespecífica de biótipos de uma espécie resistentes (Christoffoleti \& Caetano, 1998).

A tolerância de plantas daninhas a herbicidas resulta da capacidade inata da espécie em suportar aplicações desses produtos nas doses recomendadas, sem alterações marcantes em seu crescimento e/ou desenvolvimento e, embora a planta possa ser afetada, o dano é temporário e há recuperação posterior (Torres \& Fernandez-Quintanilla, 1991). Já, a resistência a herbicidas se caracteriza por sua capacidade de sobreviver e de se reproduzir após um tratamento herbicida que, sob condições normais de uso, controlaria efetivamente esta população (Naylor, 2002). A resistência não é uma característica comum inerente à população em si, mas foi selecionada por efeito da pressão de seleção (Oliveira Jr. \& Constantin, 2001).

Atualmente, entre os métodos de controle para plantas daninhas, nas culturas do arroz irrigado e da soja, o uso de herbicidas é uma das práticas mais viáveis. Contudo, a utilização contínua destes produtos resultou no aumento da proporção de populações tolerantes do gênero Digitaria (Dias, 2004). A hipótese desta pesquisa é que as populações de Digitaria que infestam regiões agrícolas no Rio Grande do Sul (RS) apresentam diferentes níveis de suscetibilidade aos herbicidas utilizados em seu controle. Assim, o objetivo 
do trabalho foi avaliar a suscetibilidade diferencial de biótipos de milhã, encontrados em lavouras no RS, aos herbicidas cyhalofop ou clethodim.

\section{Material e Métodos}

Três experimentos foram conduzidos em casa de vegetação, na Faculdade de Agronomia Eliseu Maciel (FAEM), da Universidade Federal de Pelotas (UFPel), no período de 2009 a 2011, utilizando delineamento experimental de blocos casualizados, com três repetições. Para todos os experimentos as unidades experimentais constituíram-se de recipientes plásticos com capacidade de $0,5 \mathrm{dm}^{3}$, preenchidos com solo peneirado (malha $0,5 \mathrm{~cm}$ ), classificado como Argissolo Vermelho Amarelo, de textura franco arenosa, pertencente à unidade de mapeamento Pelotas (Embrapa, 2006). Nos três experimentos a adubação foi realizada segundo análise de solo e as recomendações técnicas para as culturas de soja e arroz-irrigado (Reunião..., 2008; SOSBAI, 2009). Em cada vaso estabeleceu-se população de seis plantas de milhã, com semeadura realizada em densidade superior à desejada e posterior desbaste, aos sete dias após a emergência.

As sementes de Digitaria spp. foram coletadas em áreas de produção de arroz irrigado e soja em diferentes regiões do RS, no período compreendido entre 17 de fevereiro e 20 de março de 2009. Foram visitados 19 municípios e em cada, três localidades (lavouras), onde foram realizadas, em geral, três coletas de sementes, georreferenciadas, totalizando 169 biótipos de Digitaria spp. ocorrentes no RS.

Nas áreas de arroz irrigado realizaramse coletas em seis regiões orizícolas (IRGA, 2008): Fronteira Oeste (Itaqui e Uruguaiana); Campanha (Dom Pedrito e Rosário do Sul); Depressão Central (Cachoeira do Sul e São Sepé); Planície Costeira Interna (Camaquã e Tapes); Planície Costeira Externa (Mostardas e Viamão); e Zona Sul (Arroio Grande e Santa
Vitória do Palmar). Para representar áreas produtoras de soja foram escolhidos os municípios com maior produção no RS (IBGE, 2006): Carazinho, Cruz Alta, Ijuí, Lagoa Vermelha, Passo Fundo, Santa Bárbara do Sul e Tupanciretã.

No primeiro experimento, de novembro de 2009 a janeiro de 2010, visando verificar a suscetibilidade dos biótipos de milhã aos herbicidas cyhalofop ou clethodim, avaliaramse todos os biótipos de milhã coletados no RS que possuíam sementes viáveis, totalizando 140 biótipos estudados. O herbicida cyhalofop (180 $\left.\mathrm{g} \mathrm{L}^{-1}\right)$ foi aplicado na dose recomendada para controle de milhã na cultura do arroz irrigado (225g i.a. ha ${ }^{-1}$, com adição de $1,0 \mathrm{~L} \mathrm{ha}^{-}$ 1 de óleo vegetal - Veget $\mathrm{Oil}^{\circledR}$ ), enquanto o clethodim (240 g i.a. $\left.\mathrm{L}^{-1}\right)$ foi aplicado de acordo com as recomendações para a cultura da soja (96 g i.a. ha ${ }^{-1}$, acrescido de $0,5 \% \mathrm{v} / \mathrm{v}$ de óleo mineral - Assist $^{\circledR}$ ) (Reunião..., 2008; SOSBAI, 2009).

$\mathrm{Na}$ aplicação dos herbicidas, as plântulas de milhã se encontravam no estádio de três folhas a um afilho. Os tratamentos foram aplicados sobre as plântulas com auxílio de pulverizador costal pressurizado a $\mathrm{CO}_{2}$, munido com pontas do tipo leque 110.015 (Micron Air $\left.{ }^{\circledR}\right)$, regulado para proporcionar aplicação de $150 \mathrm{~L} \mathrm{ha}^{-1}$.

Avaliou-se o nível de controle aos 30 dias após a aplicação (DAA) dos tratamentos com herbicida, observando-se visualmente os efeitos e aplicando-se escala percentual, onde zero (\%) representou ausência de sintomas e $100 \%$ a morte das plantas (Frans et al., 1986). Submeteram-se os dados obtidos à análise de variância e, em sendo significativo o teste "f" $(\mathrm{p} \leq 0,05)$, compararam-se as médias de controle dos acessos de milhã adotando-se o intervalo de confiança $(p \leq 0,05)$.

No período de janeiro a fevereiro de 2011, foram realizados dois experimentos de curva dose resposta para avaliar o controle químico de oito biótipos, selecionados no experimento anterior, todos pertencentes à 
espécie Digitaria ciliaris, que apresentaram maior e menor tolerâncias aos herbicidas cyhalofop ou clethodim. Arranjaram-se os tratamentos em esquema fatorial, em que o fator A comparou os oito biótipos de milhã citados, enquanto o fator B constou de cinco doses do herbicida cyhalofop $(0 ; 112,5 ; 225$; 450 e 900 g i.a. ha ${ }^{-1}$ ) (segundo experimento) ou clethodim $\left(0 ; 48 ; 96 ; 192\right.$ e 384 g i.a. ha $\left.{ }^{-1}\right)$ (terceiro experimento). Essas doses corresponderam a $0,1 / 2,1,2$ e 4 vezes as doses recomendadas para as culturas do arroz e soja, respectivamente (Reunião..., 2008; SOSBAI, 2009). Adicionou-se $1,0 \mathrm{~L} \mathrm{ha}^{-1}$ de óleo vegetal $\left(\right.$ Veget Oil $^{\circledR}$ ) ao herbicida cyhalofop e $0,5 \% \mathrm{v} / \mathrm{v}$ de óleo mineral (Assist ${ }^{\circledR}$ ) para clethodim. As plântulas de milhã apresentavam estádio de um a dois afilhos no momento da aplicação do tratamento herbicida. A aplicação dos tratamentos e a forma de avaliação visual aos 30 DAA procedeu de forma semelhante a anteriormente citada.
Os dados obtidos foram analisados quanto à sua homocedasticidade e, posteriormente, submetidos à análise de variância $(\mathrm{p} \leq 0,05)$. Quando a probabilidade " $\mathrm{f}$ " foi significativa, analisaram-se os dados por regressão, aplicando-se o modelo de equação logístico não linear:

$$
\mathrm{Y}=\mathrm{a} /\left(1+(\mathrm{x} / \mathrm{x} 0)^{\mathrm{b}}\right)
$$

Onde: $\mathrm{Y}=$ controle $(\%) ; \mathrm{a}=$ máximo controle; $\mathrm{x}=$ dose do herbicida $\left(\mathrm{g}\right.$ i.a. ha $\left.{ }^{-1}\right) ; \mathrm{x} 0$ $=$ dose herbicida $\left(\mathrm{g}\right.$ i.a. ha $\left.{ }^{-1}\right)$ que provê $50 \%$ de controle e $b=$ declividade da curva (Seefeldt et al., 1995).

\section{Resultados e Discussão}

No primeiro experimento, os resultados de controle aos 30 DAA dos herbicidas cyhalofop ou clethodim apresentaram significância estatística, indicando haver diferenças entre as populações de milhã na resposta ao efeito dos herbicidas (Figura 1).

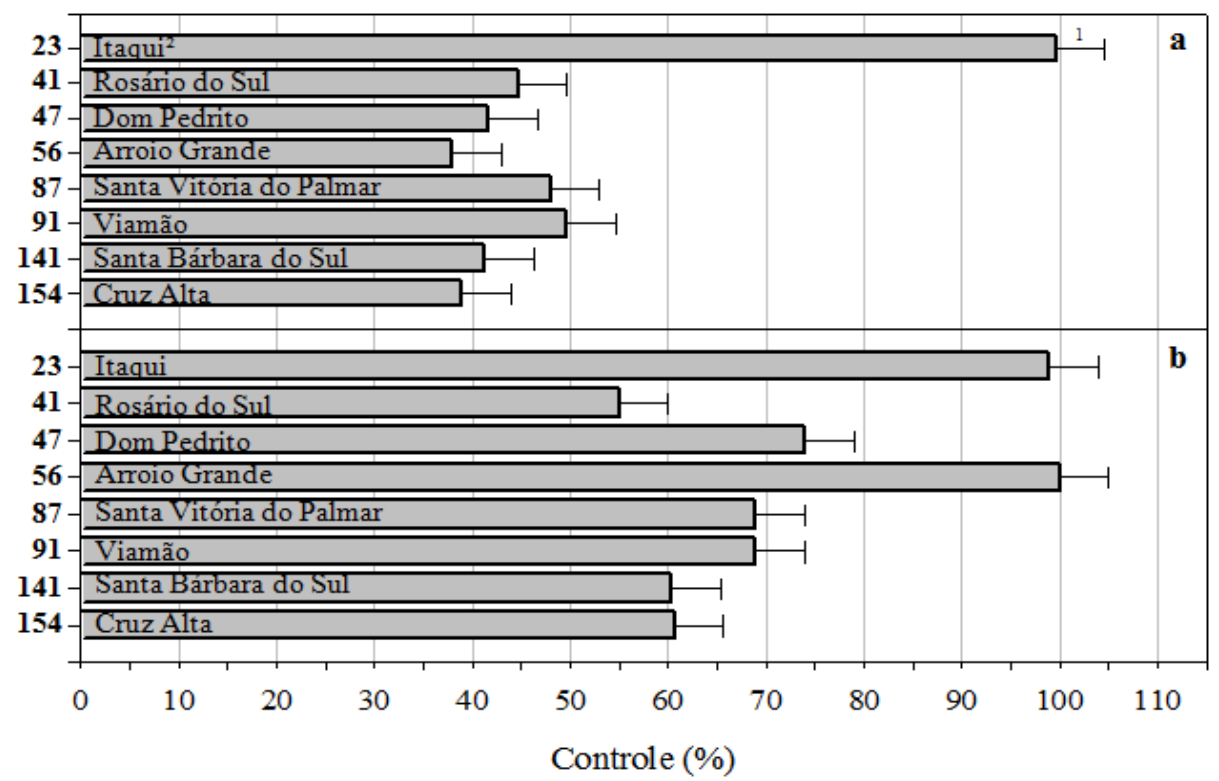

Figura 1. Controle de Digitaria ciliaris, provenientes de diferentes regiões do Rio Grande do Sul, avaliado 30 dias após a aplicação dos herbicidas cyhalofop (225 g i.a. ha ${ }^{-1}$ ) (a) e clethodim $\left(96\right.$ g i.a. ha $\left.{ }^{-1}\right)(b) .{ }^{1}$ Intervalo de confiança $(\mathrm{p} \leq 0,05) ;{ }^{2}$ Município onde foi coletado.

A aplicação dos herbicidas pertencentes à espécie D. ciliaris que proporcionou controle dos biótipos entre 38 e apresentaram maior e menor tolerâncias, os $100 \%$, sendo selecionados oito biótipos quais foram utilizados nos demais estudos. Os 
biótipos selecionados foram: 23 (Itaqui - 53¹9'52" W) e 154 (Cruz Alta - 28³7'21" S 29²0’28" S 56³7'55” W), 41 (Rosário do Sul - 30¹6'58” S 54 54'11” W), 47 (Dom Pedrito $53^{\circ} 41^{\prime} 23^{\prime \prime} \mathrm{W}$ ) (Figura 1).

Os resultados obtidos nos experimentos

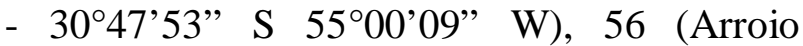
Grande - 32 16 '54” S 5304'32” W), 87 (Santa Vitória do Palmar - 32 54'05" S 5243'32" W), 91 (Viamão - 3006'35" S 5041'40” W), 141 (Santa Bárbara do Sul - 28²2'58" S de curva de dose resposta com os biótipos de milhã e os herbicidas cyhalofop ou clethodim apresentaram significância estatística, indicando haver diferenças entre as populações de milhã e os herbicidas estudados, em todas as avaliações realizadas (Figura 2 e 3).

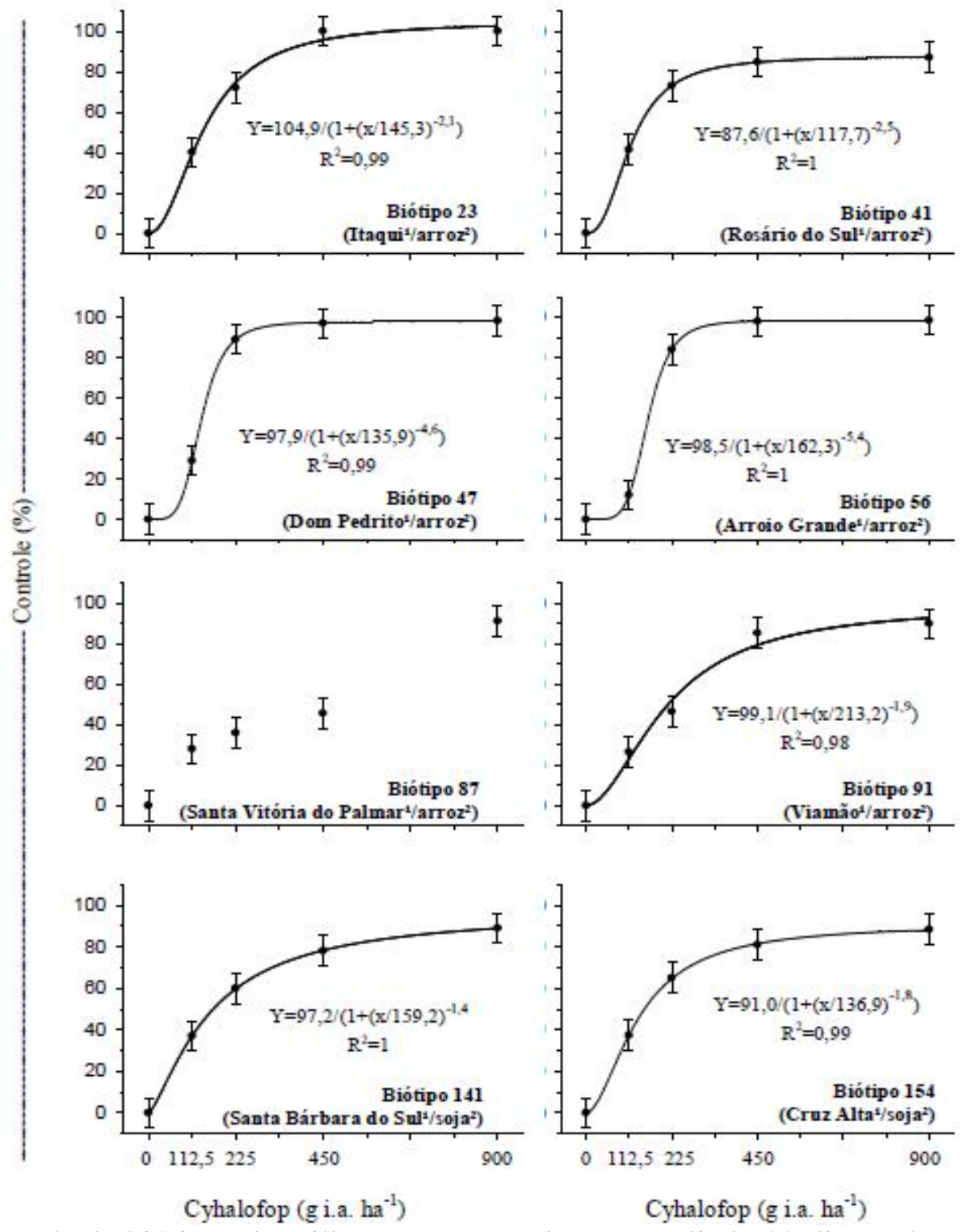

Figura 2. Controle de biótipos de milhã (Digitaria ciliaris), avaliado 30 dias após a aplicação do herbicida cyhalofop. Capão do Leão/RS, 2011. As barras verticais representam os intervalos de confiança $(\mathrm{p} \leq 0,05) .{ }^{1}$ Município de origem; ${ }^{2}$ Espécie cultivada na área. 
O controle da milhã aos 30 DAA, em resposta às doses crescentes de cyhalofop, demonstrou que as populações testadas apresentaram efeito negativo relativo ao incremento da dose do herbicida. Os dados ajustaram-se à equação de regressão sigmoidal do tipo logístico para todos os biótipos, à exceção do biótipo 87, que não apresentou ajuste ao modelo (Figura 2). Os valores do coeficiente de determinação $\left(\mathrm{R}^{2}\right)$ variaram de 0,98 a 1,0 e os valores do parâmetro " $b$ " foram significativos, demonstrando ajuste satisfatório dos dados ao modelo.

Adotou-se como critério de comparação a inclinação da curva, de forma que quanto maior o valor do parâmetro " $b$ " da equação, maior tolerância ao herbicida. Desse modo, verificou-se que os biótipos que apresentaram maior tolerância foram 91, 141 e 154 (b = -1,9; $-1,4$ e $-1,8$, respectivamente), com controles entre 50 e $60 \%$, proporcionados pela dose recomendada do herbicida cyhalofop. Embora os dados do biótipo 87 não tenham se ajustado à equação, cabe salientar que este demonstrou também ser tolerante ao cyhalofop (Figura 2). Para os biótipos 23 e 41 (b $=-2,1$ e $-2,5$, respectivamente), obteve-se maior efeito do herbicida cyhalofop, com controle próximo a $75 \%$. Por fim, as populações identificadas como 47 e 56 ( $b=-4,6$ e $-5,4$, respectivamente) foram suscetíveis ao cyhalofop, com eficiência superior a $85 \%$ de controle.

O uso contínuo de herbicidas sobre espécies de milhã resultou na seleção de populações tolerantes desse gênero de plantas daninhas (Dias et al., 2003; Dias, 2004), sendo que a ineficácia da dose comercial de cyhalofop já foi registrada no Brasil para população de $D$. ciliaris resistente aos inibidores de ACCase (López-Ovejero et al., 2006). As diferenças observadas na suscetibilidade ao herbicida cyhalofop permitem inferir que no Rio Grande do Sul há populações de milhã tolerantes a este herbicida. Salienta-se que, no presente estudo, as unidades experimentais não foram inundadas, sendo que esta prática após a aplicação do herbicida poderá auxiliar na ação do controle químico.

O aumento na infestação de milhã nas áreas de arroz irrigado pode decorrer do fato de que entre os herbicidas recomendados para esta cultura, poucos possuem espectro de ação que contemple efeito sobre milhã, permitindo incremento na população destas espécies (SOSBAI, 2009). Ainda, os produtos registrados para controle de milhã podem não estar sendo eficientes no controle de determinadas populações, como sugerem os resultados do presente estudo.

Para o experimento com clethodim, as populações de milhã responderam de forma negativa às doses crescentes do herbicida aos 30 DAA (Figura 3). Os dados ajustaram-se à equação de regressão sigmoidal do tipo logístico, sendo que os valores do coeficiente de determinação $\left(\mathrm{R}^{2}\right)$ variaram de 0,99 a 1,0 , assim como os valores do parâmetro " $b$ " foram significativos, demonstrando ajuste satisfatório dos dados ao modelo.

A eficiência de controle aumentou com o incremento na dose do herbicida, atingindo níveis superiores a $90 \%$ com $1 \mathrm{x}$ a dose recomendada do clethodim (96 g i.a. ha ${ }^{-1}$ ) para todos os biótipos estudados, demonstrando que as populações de milhã foram suscetíveis ao referido herbicida (Figura 3). Ainda, verificouse que as diferenças entre as populações, observadas nas inclinações das curvas, derivaram do controle proporcionado pela metade da dose recomendada do clethodim para milhã (48 g i.a. ha ${ }^{-1}$ ). Em relação a essa dose, verificou-se que as populações 47 e 87 foram as mais suscetíveis, seguindo-se os biótipos 56 e 91, enquanto os menores efeitos ocorreram nos biótipos 41, 141, 154 e 23. 

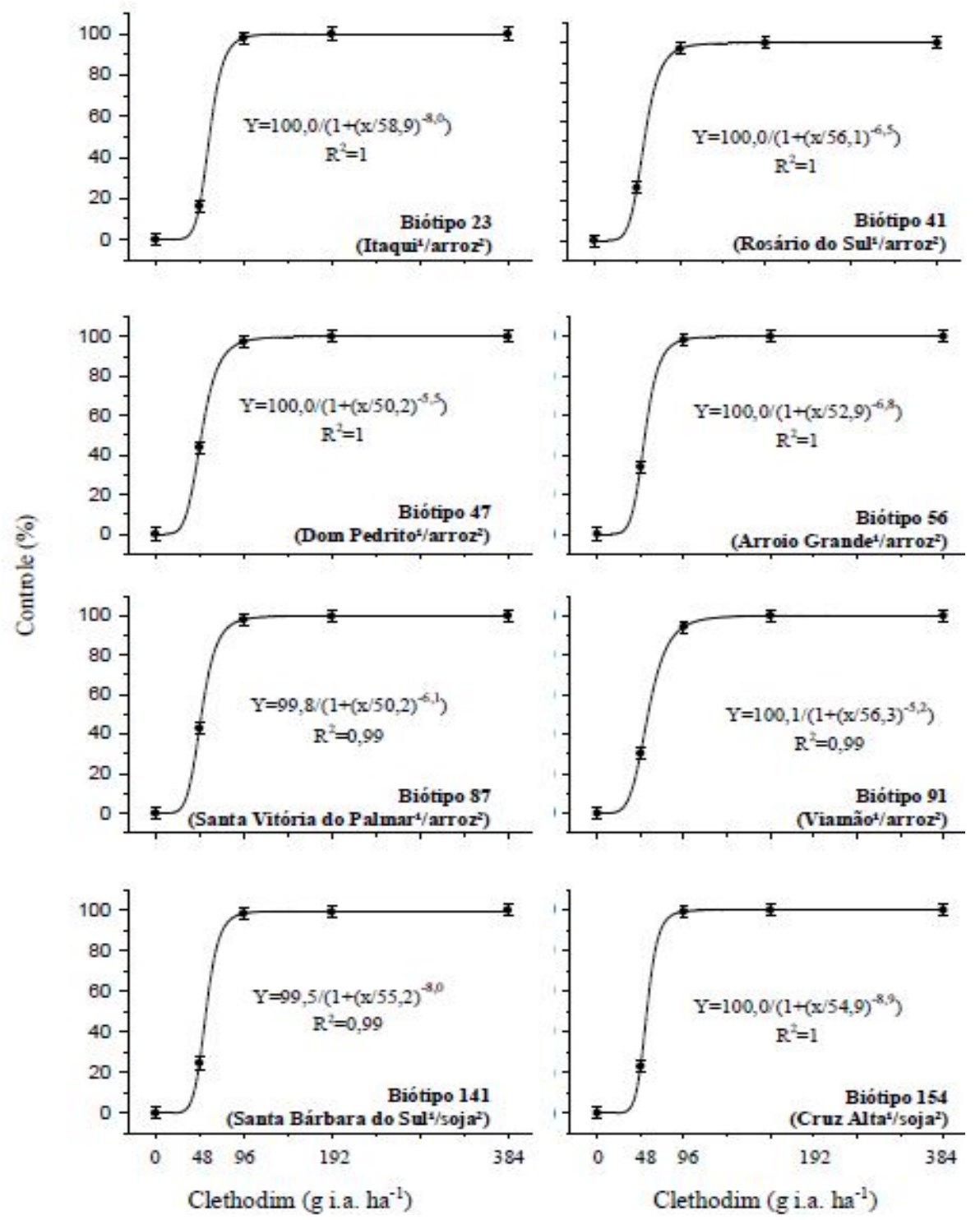

Figura 3. Controle de biótipos de milhã (Digitaria ciliaris), avaliado 30 dias após a aplicação do herbicida clethodim. Capão do Leão/RS, 2011. As barras verticais representam os intervalos de confiança $(\mathrm{p} \leq 0,05) .{ }^{1}$ Município de origem; ${ }^{2}$ Espécie cultivada na área.

Estudos relataram a ocorrência de diferenças na suscetibilidade entre populações de uma espécie quando o herbicida é aplicado em doses menores que a recomendada para controle (Dias et al., 2003). A tolerância diferencial a determinado herbicida dentro da espécie ocorre normalmente, sendo preciso verificar se os biótipos são controlados com a dose registrada e recomendada do herbicida (Hartzler \& Boerboom, 2006). Assim, as plantas provenientes de populações de milhã encontradas no RS manifestaram-se suscetíveis ao herbicida clethodim. Contudo, a milhã já apresenta no Brasil populações resistentes a herbicidas do mesmo grupo químico que o clethodim, sendo eles o sethoxydim e tepraloxydim (López-Ovejero et al., 2005).

Segundo Gelmine et al. (2001), o herbicida clethodim é eficiente no controle de milhã, inclusive em populações que apresentam resistência a outros inibidores da ACCase. No entanto, Barroso et al. (2010) 
mencionaram que a dose comercial de clethodim não atingiu $80 \%$ de controle em população de $D$. ciliaris, considerada suscetível. Ainda, controle inferior $40 \%$ foi relatado em população resistente a outros inibidores de ACCase (López-Ovejero et al., 2006), além de ocorrência de resistência ao clethodim em D. sanguinalis (Wiederholt \& Stoltenberg, 1995).

Cabe salientar que no presente estudo, não foi possível relacionar as informações do local de origem das populações de milhã e manejo realizado nas lavouras de arroz ou de soja, com a suscetibilidade diferencial apresentada pelas plantas. No entanto, se observou que a abundância de milhã, independentemente da espécie, está relacionada com a eficácia do herbicida utilizado na lavoura. Em geral, encontrou-se menor população de milhã nas lavouras de arroz irrigado quando o herbicida imazethapyr+imazapic foi aplicado e nas áreas cultivadas com soja que receberam a aplicação do herbicida glyphosate. Outro fator determinante para o nível de infestação é o manejo da lâmina de água no arroz, pois em lavouras com maior declive, com consequente dificuldade na manutenção da lâmina de água, encontraram-se maiores populações de milhã.

\section{Conclusões}

Todas as populações de milhã (Digitaria ciliaris), coletadas em lavouras de arroz e soja dos municípios do Rio Grande do Sul (RS) foram suscetíveis ao herbicida clethodim, quando aplicado na dose recomendada (96g i.a. ha ${ }^{-1}$ ). A suscetibilidade da milhã ao herbicida cyhalofop foi diferencial entre biótipos, com quatro populações $(87,91$, 141 e 154) apresentando tolerância a este herbicida.

\section{Referências}

BALBINOT JR., A.A. et al. Competitividade de cultivares de arroz irrigado com cultivar simuladora de arroz-vermelho. Pesquisa Agropecuária Brasileira, v.38, n.1, p.53-59, 2003.

BARROSO, A.L.L. et al. Eficácia de herbicidas inibidores da ACCase no controle de gramíneas em lavouras de soja. Planta Daninha, v.28, n.1, p.149-157, 2010.

BURKE, I.C. et al. A seedling assay to screen aryloxyphenoxypropionic acid and cyclohexanedione resistance in johnsongrass (Sorghum halepense). Weed Technology, v.20, n.4, p.950-955, 2006.

CHRISTOFFOLETI, P.J.; CAETANO, R.S.X. Soil seed banks. Scientia Agrícola, v.55, n.esp., p.74-78, 1998.

DIAS, N.M.P. et al. Absorção e translocação do herbicida diuron por espécies suscetível e tolerante de capim-colchão (Digitaria spp.). Planta Daninha, v.21, n.2, p.293-300, 2003.

DIAS, N.M.P. Tolerância de espécies de capim-colchão (Digitaria spp.) a herbicidas na cultura da cana-de-açúcar. 2004. 118f. Tese (Doutorado em Fitotecnia) - Escola Superior de Agricultura "Luiz de Queiroz", Piracicaba, 2004.

EMBRAPA. Empresa Brasileira de Pesquisa Agropecuária. Centro Nacional de Pesquisa de Solos. Sistema Brasileiro de Classificação de Solos. Brasília: 2006. 306p.

FLECK, N.G. et al. Interferência de Raphanus sativus sobre cultivares de soja durante a fase vegetativa de desenvolvimento da cultura. Planta Daninha, v.24, n.3, p.425-434, 2006.

FONTANA, L.C. Identificação de espécies, suscetibilidade a herbicidas e habilidade competitiva de milhã (Digitaria spp.) no estado do Rio Grande do Sul. 2011.119f. Tese (Doutorado em Fitossanidade) - Programa de Pós-graduação em Fitossanidade, Universidade Federal de Pelotas.

FRANS, R. et al. Experimental design and techniques for measuring and analyzing plant 
responses to weed control practices. In: CAMPER, N.D. (Ed.) Research Methods in Weed Science. 3 ed. Champaign: Southern Weed Science Society, 1986. 37p.

GALON, L. et al. Estimativa das perdas de produtividade de grãos em cultivares de arroz (Oryza sativa) pela interferência do capimarroz (Echinochloa spp.). Planta Daninha, v.25, n.3, p.697-707, 2007.

GELMINE, G.A.; MATTOS, J.B.S.; NOVO, M.C.S.S. Avaliação da eficiência do herbicida fenoxaprop-p-ethyl aplicado em pósemergência da cultura da cebola. Ecossistema, v.26, n.2, p.135-138, 2001.

HARTZLER, B.; BOERBOOM, C. Understanding glyphosate to increase performance. Iowa: Academic Press, 2006. $8 \mathrm{p}$.

IBGE - Instituto Brasileiro de Geografia e Estatística - Produção Agrícola Municipal de 2006. Disponível em: <http://www.ibge.gov .br/home/estatistica/economia/pamclo/2002_20 06/pamclo 2002_2006.pdf> Biótipo em: 25 abr. 2008.

IRGA - Instituto Rio Grandense do Arroz Mapa das regiões arrozeiras do RS. Disponível em:

<http://www.irga.rs.gov.br/index.php?action=p ub_mapa> Biótipo em: 25 abr. 2008.

LÓPEZ-OVEJERO, R.F. et al. Alternativas de manejo químico da Planta Daninha Digitaria ciliaris resistente aos herbicidas inibidores da ACCase na cultura de soja. Planta Daninha, v.24, n.2, p.407-414, 2006.

LÓPEZ-OVEJERO, R.F. et al. Resistência de populações de capim-colchão (Digitaria ciliaris) aos herbicidas inibidores da acetil CoA carboxilase. Planta Daninha, v.23, n.3, p.543-549, 2005.

NAYLOR, R.E.L. Weed management handbook. 9.ed. Oxford: British Crop Protection Council, 2002. 423p.
OLIVEIRA JR., R.S.; CONSTANTIN, J. Plantas daninhas e seu manejo. Guaíba: Agropecuária, 2001. 362 p.

REUNIÃO DE PESQUISA DA SOJA DA REGIÃO SUL. Indicações técnicas para a cultura de soja no Rio Grande do Sul e em Santa Catarina 2008-2009. Porto Alegre: FEPAGRO, 2008. 144p.

SEEFELDT, S.S.; JENSEN, J.E.; FUERST, E.P. Log-logistic analysis of herbicide doseresponse relationships. Weed Technology, v.9, n.2, p.218-227, 1995.

SILVA, M.R.M.; DURIGAN, J.C. Períodos de interferência das plantas daninhas na cultura do arroz de terras altas. II - cultivar caiapó. Bragantia, v.68, n.2, p.373-379, 2009.

SOSBAI - Sociedade Sul-Brasileira de Arroz Irrigado. Arroz irrigado: recomendações técnicas da pesquisa para o Sul do Brasil, Pelotas: SOSBAI, 2009. 161p.

TORRES, L.G.; FERNANDESQUINTANILLA, C. Fundamentos sobre malas hierbas y herbicidas. Madrid: Mundiprensa, 1991. 348p.

VARGAS, L.; ROMAN, E.S. Manejo e controle de plantas daninhas na cultura da soja. Passo Fundo: Embrapa Trigo, 2006, 23p.

VIDAL, R.A.; MEROTTO JR., A. Herbicidologia. 1ed. Porto Alegre: Evangraf, 2001. 152p.

WIEDERHOLT, R.J.; STOLTENBERG, D.E. Cross-Resistance of a large crabgrass (Digitaria sanguinalis) accession to aryloxyphenoxypropionate and cyclohexanodione herbicides. Weed Technology, v.9, n.3, p.518-524, 1995. 